\title{
PENGGUNAAN MODELPEMBELAJARAN INSIDE-OUTSIDE CIRCLE PADA MATA KULIAH BIOLOGI UMUM
}

\author{
Relsas Yogica \\ Fakultas Matematika dan Ilmu Pengetahuan Alam, Universitas Negeri Padang \\ relsasyogica.1103992@gmail.com
}

\begin{abstract}
Classroom learning and laboratory practic are spesific aspects of learning in university, focused on students activities. Students must be able to improve theirself become someone who expert to find an information, keep and save it, and share that thing to others. Hopely, a ready person who will hold the world chances in many life aspects will be created. This proceess is impossible without hands of teacher and all elements in department, faculty, university and government. But, the smallest factor that should exist in first step is teacher. They must always understand their own class and their student's problem in the class. Writer observed a class from Physic Development in first year degree in Basic Biology subject. This course is one of 4 courses that should be taken by first year students. Writer saw many students felt tedious. For example, they looked sleepy, they went out in high frequency, and some others came late to the classroom. This condition should not happen. Writer had use a learning model namely inside-outside circle to solve this problem. In logic, writer had try a new learning method to make new sense. Writer looked for informations about this model before it was practiced in the class. The development of treatment was observed weekly. Research results are students feel happy and overall they got a good grade in last exam.
\end{abstract}

Keywords: learning, model, inside-outside circle

\section{PENDAHULUAN}

Mekanisme pembelajaran di tingkat universitas tidak memiliki perbedaan yang jauh jika dibandingkan dengan pelaksanaan pembelajaran di tingkat sekolah menengah, harapannya adalah kemampuan peserta didik untuk menguasai pembelajaran dan membangun makna belajarnya sendiri. Prinsip dasar ini tersirat dalam Peraturan Menteri Pendidikan Nasional No.41 tahun 2007 terkait standar proses, dinyatakan bahwa pembelajaran selayaknya berlangsung sepanjang hayat dengan mekanisme pembudayaan dan pemberdayaan peserta didik.

Pada tingkat universitas, mahasiswa adalah peserta didik yang seharusnya bertindak sebagai individu yang memahami posisinya dalam dunia pendidikan. Pembelajaran seharusnya memfokuskan diri kepada kemampuan mahasiswa untuk memahami, menjelaskan dan mengaplikasikan ilmu yang diperolehnya. Tujuannya adalah agar tercipta individu yang kelak dapat bersosialisasi dengan masyarakat dan mampu membagikan ide-ide inovatif untuk perbaikan secara berkelanjutan.

Harapan tersebut tidak mungkin akan tercapai jika hanya mahasiswa yang menginginkan perubahan diri. Dalam lingkungan universitas, tidak hanya mahasiswa yang menjadi penentu keberhasilan. Faktor lain yang tidak kalah berperannya dalam penentuan keberhasilan mahasiswa dimasanya adalah dosen. Dosen berperan sebagai pendidik, pembimbing dan penasehat bagi mahasiswa. Keberadaan dosen pada posisi yang tepat bagi mahasiswa akan memberikan motivasi tersendiri.

Interaksi antara dosen dan mahasiswa pada hakikatnya tidak mesti di dalam ruang kelas saat perkuliahan berlangsung, namun pertemuan tersebut boleh dikatakan sebagai dominansi dosen terhadap waktu mahasiswa. Dosen akan dengan mudah mengembangkan diri mahasiswa jika ia dapat mengakses mahasiswa tersebut.Saat tujuan pengembangan diri dan potensi mahasiswa ingin dilakukan, sebaiknya memang dimulai dari ruang kelas pada saat pertemuan tatap muka. Pada saat itu dosen dapat mengobservasi dan menilai kualitas mahasiswa. Hal ini merupakan kemampuan alamiah dosen yang pada dasarnya penting. Agar dosen dengan mudah memetakan kelas sesuai dengan karakteristik mahasiswa masing-masing. Pemahaman terhadap mahasiswa akan memunculkan ide dosen untuk menciptakan perkuliahan yang produktif dan menyenangkan.

Salah satu mata kuliah yang harus diambil bagi mahasiswa tahun pertama di FMIPA 
Universitas Negeri Padang adalah mata kuliah biologi umum. Mata kuliah ini adalah salah satu dari empat mata kuliah TPB. Tidak hanya mahasiswa dari jurusan biologi, mahasiswa jurusan kimia, matematika dan fisika harus mengambil mata kuliah ini.

Penulis melakukan observasi pada program studi fisika selama beberapa kali pertemuan. Kesimpulan pengamatan adalah mereka terlihat mengantuk, sering keluar masuk ruangan dan beberapa yang lain datang terlambat, sehingga dapat dikatakan bahwa pembelajaran biologi umum tersebut cenderung membosankan bagi mahasiswa. Untuk memperbaiki kondisi ini, penulis berhipotesis bahwa pembelajaran dengan menggunakan model inside-outside circle akan membantu menarik minat belajar mahasiswa. Lie (2002) menjelaskan bahwa model pembelajaran ini akan memberikan kesempatan kepada mahasiswa untuk berbagi dengan rekannya dalam waktu yang bersamaan/ serentak. Hal ini didasari kepada penelitian-penelitian yang telah dilakukan oleh peneliti lain yang menjadi sumber referensi bagi penulis saat ini.

Tujuan penelitian ini adalah untuk membuktikan hipotesis bahwa pembelajaran dengan menggunakan model inside-outside circleakan meningkatkan minat belajar pada mata kuliah biologi umum bagi mahasiswa tahun pertama program studi fisika. Peningkatan minat tersebut diharapkan dapat pula meningkatkan aktifitas mereka dalam proses pembelajaran serta nilai akhir yang akan mereka peroleh.

\section{KAJIAN LITERATUR}

Semua model pembelajaran ditandai dengan adanya struktur tugas, struktur tujuan, dan struktur penghargaan. Struktur tugas mengacu kepada cara pembelajaran diorganisasikan dan jenis kegiatan yang dilakukan oleh siswa di dalam kelas. Struktur tujuan merupakan kadar saling ketergantungan siswa pada saat mereka mengerjakan tugas. Struktur tujuan terdiri dari tiga macam, yaitu individualistik, kompetitif, dan kooperatif. Struktur penghargaan merupakan penghargaan yang diperoleh siswa atas prestasinya (Lufri. 2007)

Model pembelajaran kooperatif adalah model pembelajaran yang menekankan pada kegiatan belajar bersama bagi peserta didik. Tuntutan sederhananya adalah kemampuan peserta didik untuk bersama dan berbagi pengetahuannya dengan rekan dalam kelompok maupun antar kelompok. Pembelajaran kooperatif mempunyai ciri adanya struktur tugas, tujuan dan penghargaan yang bersifat kooperatif, yaitu mengutamakan kerjasama dalam pelaksanaannya. Dalam hal ini mahasiswa dituntut agar bisa melakukan aktifitas belajar dan menemukan jawaban pertanyaan dengan cara bekerjasama dengan rekannya. Sehingga selain akan menciptakan keaktifan dalam belajar, juga akan melatih jiwa sosial yang tinggi.

Salah satu model pembelajaran yang telah dikembangkan oleh Spencer Kagan pada tahun 1993 adalah model pembelajaran insideoutside circle (Lie. 2002). Model pembelajaran ini cocok digunakan pada materi yang membutuhkan pertukaran informasi bagi mahasiswa. Keunggulan model pembelajaran ini adalah memungkinkan mahasiswa untuk berbagi informasi dengan mahasiswa lain dalam waktu yang singkat. Sedangkan kekurangan model IOC adalah membutuhkan ruangan yang cukup luas untuk dapat dilaksanakan. Dalam penelitian ini, persoalan tersebut tidak menjadi masalah, karena ruang kelas cukup besar dan jumlah mahasiswa hanya 38 orang.

Prosedur pelaksanaan perkuliahan dengan model pembelajaran IOC pada penelitian ini adalah sebagai berikut:

a. Pada minggu sebelumnya, dosen membagi materi perkuliahan menjadi 19 sub pokok materi. Sub pokok materi tersebut dijabarkan oleh mahasiswa menjadi penjelasan-penjelasan.

b. Mahasiswa dibagi menjadi dua kelompok. Tiap kelompok memiliki anggota 19 orang (jumlah satu kelas adalah 38 orang).

c. Kelompok pertama membentuk lingkaran yang menghadap keluar. Mahasiswa pada lingkaran ini lah yang bertugas mengumpulkan informasi yang telah diberikan.

d. Kelompok kedua membentuk lingkaran yang sama dibagian luar kelompok pertama. Kelompok kedua menghadap ke arah dalam. Sehingga mahasiswa berhadapan.

e. Masing-masing mahasiswa pada lingkaran dalam memberikan informasi kepada mahasiswa yang ada pada lingkaran luar secara bersamaan. 
f. Setelah informasi selesai, mahasiswa lingkaran luar berputar searah jarum jam dan menemukan pasangan baru, dan informasi yang baru dikumpulkan lagi.

g. Diakhir pembelajaran, semua mahasiswa lingkaran luar telah mengumpulkan semua informasi.

\section{METODE PENELITIAN}

Penelitian ini adalah penelitian tindakan kelas. Pengamatan terhadap perkembangan mahasiswa dilakukan setiap minggu dengan jumlah pertemuan keseluruhan adalah 8 kali pertemuan (8 minggu). Sampel penelitian adalah mahasiswa tahun pertama program studi fisika yang berjumlah 38 orang mahasiswa. Penelitian dilakukan setiap hari Rabu, pukul 13.20 sampai 15.50 WIB. Dalam penelitian ini tidak ada kelas pembanding.

\section{HASIL DAN PEMBAHASAN}

Aktifitas mahasiswa yang menjadi pengamatan pada penelitian ini adalah:

a. Bertanya kepada dosen (aktifitas A)

b. Bertanya kepada rekan (aktifitas B)

c. Menjawab pertanyaan dosen (aktifitas C)

d. Menjawab pertanyaan rekan (aktifitas D)

e. Memberikan penjelasan awal (aktifitas E)

f. Memberikan kritik dan perbaikan (aktifitas F)

g. Menyimpulkan materi perkuliahan (aktifitas G)

Semua faktor aktifitas tersebut diamati dalam perkuliahan dan dievaluasi setiap minggu. Hasil pengamatan aktifitas dapat dilihat pada Gambar 1.

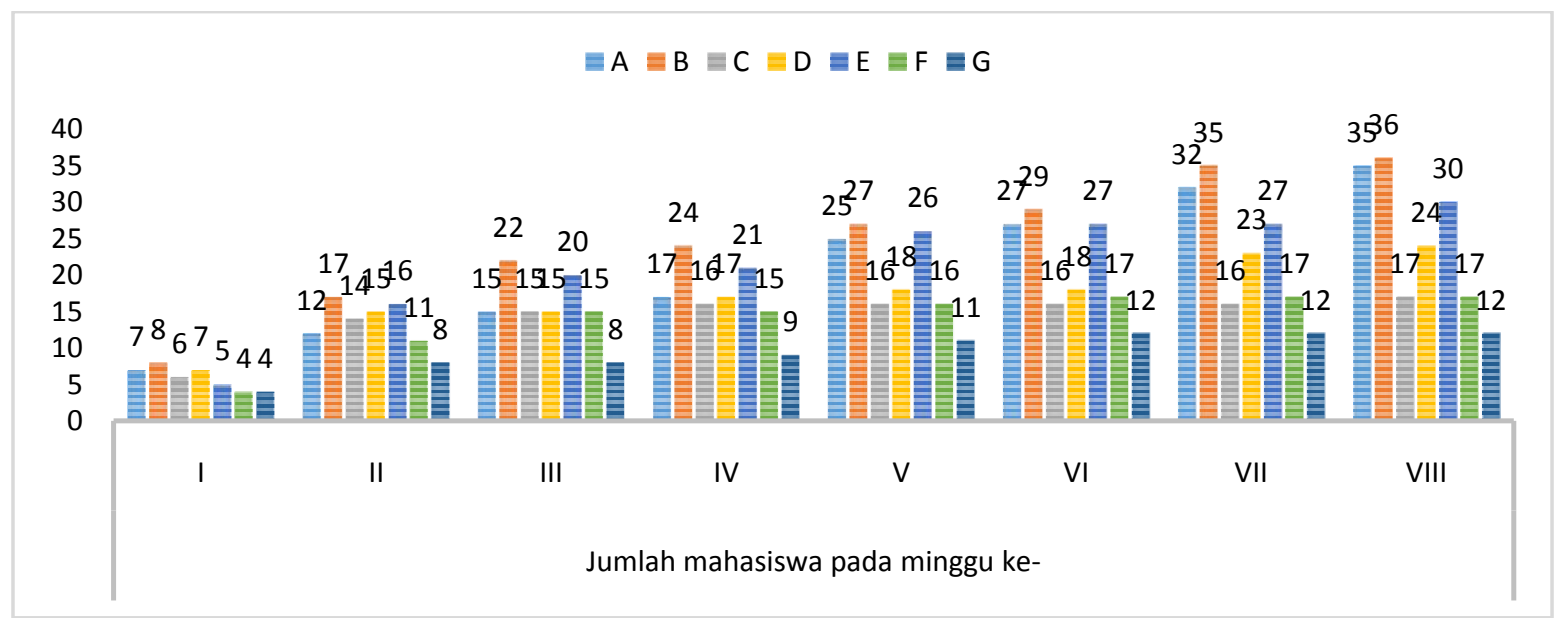

Gambar 1. Perkembangan aktifitas mahasiswa

Berdasarkan gambar di atas, dapat kita lihat bahwa semua aspek aktifitas mengalami peningkatan dari minggu-minggu sebelumnya. Minggu ke-I adalah saat dimana perkuliahan dengan menggunakan model pembelajaran inside-outside circle dimulai. Ratio mahasiswa terbanyak pada minggu ke-VIII adalah pada aktifitas B, yakni bertanya kepada rekan, sementara ratio mahasiswa terkecil pada minggu yang sama adalah pada aktifitas G, yakni menyimpulkan materi perkuliahan. Mahasiswa dengan menggunakan model ini merasa nyaman dan santai dalam pembelajaran. Mereka merasa percaya diri untuk bertanya, sehingga dalam pembelajaran sebagian besar aktifitas ada pada kegiatan tanya jawab antar mahasiswa. Di lain sisi, kegiatan menyimpulkan materi adalah kegiatan terakhir untuk setiap pertemuan. Setelah satu atau dua orang mahasiswa yang diberikan kesempatan untuk menyimpulkan materi, rekan-rekannya yang lain hanya menambahkan sebagian kecil dari kesimpulan tersebut.Sehingga dirasakan wajar jika ratio menjadi kecil. Ditambah dengan sedikitnya waktu yang tersedia untuk mahasiswa jika masing-masing individu diberikan kesempatan untuk menyimpulkan materi. Namun dalam pengamatan selama penelitian, pada saat peneliti meminta kesediaan mahasiswa untuk menyimpulkan materi, sebagian besar mahasiswa mengajukan diri.

Selain aktifitas mahasiswa, hasil belajar mahasiswa juga menjadi bahan pengamatan penelitian. Hasil belajar mahasiswa dapat dilihat pada Gambar 2. 


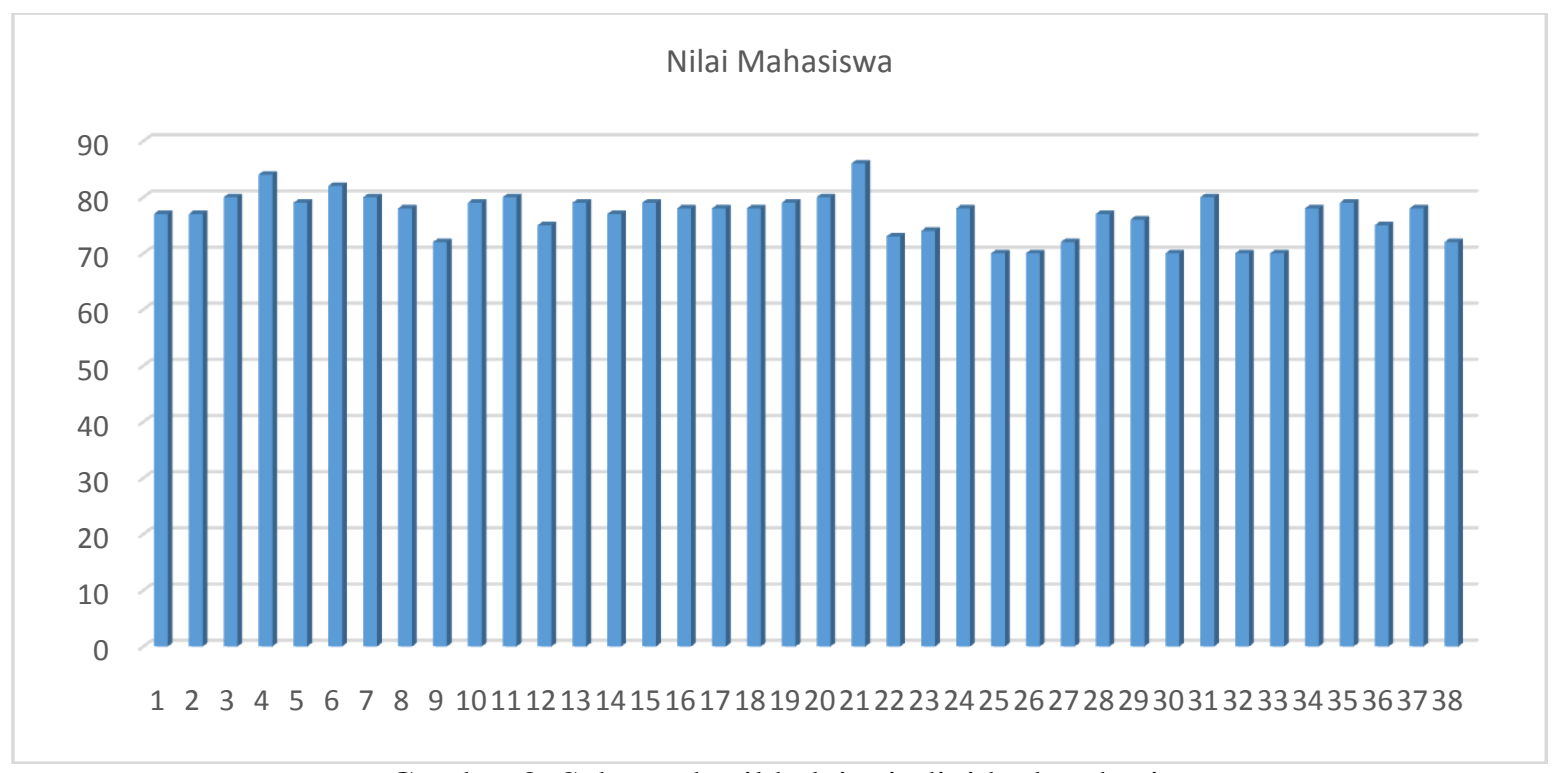

Gambar 2. Sebaran hasil belajar individual mahasiswa

Berdasarkan grafik tersebut dapat dilihat sebaran hasil belajar mahasiswa setelah pelaksanaan pembelajaran dengan menggunakan model IOC. Nilai mahasiswa tertinggi adalah 86 dan nilai terendah adalah 70. Rata-rata nilai adalah 77. Konversi hurufnya adalah $\mathrm{B}+$ dengan mutu baik sekali. Hasil belajar ini menunjukkan bahwa pembelajaran menghasilkan nilai positif bagi mahasiswa. Jika dibandingkan rata-rata hasil ujian tengah semester dengan rata-rata hasil ujian akhir semester, rentangnya adalah 23 poin. Kenaikan ini dinilai signifikan.

Telah banyak peneliti yang melakukan penelitian menggunakan model IOC dengan harapan hasil positif pada hasil pembelajaran, diantaranya adalah:

a. Putranjaya, dkk (2013) menjelaskan bahwa penggunaan model IOC dapat meningkatkan hasil belajar siswa kelas VII.

b. Cahyanti (2015) menjelaskan bahwa dengan penerapan model IOC dalam pembelajaran matematika SD dapat meningkatkan kemampuan siswa menyelesaikan masalah, khususnya matematika.

c. Aryani (2015) menjelaskan adanya peningkatan aktivitas siswa setelah pelaksanaan pembelajaran dengan menggunakan model IOC.

d. Andhika, dkk (2013) menjelaskan bahwa hasil belajar siswa IPS dapat ditingkatkan dengan bantuan model pembelajaran IOC.

e. Arfinanti (2010) menjelaskan bahwa semua siswa dapat mencapai KKM setelah menggunakan model IOC dalam pembelajaran matematika.

Masih banyak lagi penelitian yang dilakukan terkait penggunaan model IOC dan semua menunjukkan hasil yang positif. Penelitian yang dijadikan bahan rujukan penelitian ini dilaksanakan di tingkat sekolah dasar dan sekolah menengah, dengan hasil yang ditemukan sekarang dapat menambah informasi bagi peneliti selanjutnya. Bahwa model pembelajaran inside-outside circle tidak hanya memberikan pengaruh positif pada siswa sekolah, namun juga bagi mahasiswa di tingkat universitas.

\section{KESIMPULAN}

Kesimpulan penelitian ini adalah model pembelajaran IOC untuk mahasiswa program studi fisika tahun pertama yang mengikuti perkuliahan biologi umum memberikan pengaruh yang positif pada peningkatan aktifitas dan hasil belajar. Disarankan untuk penulis dan peneliti lainnya agar tidak berhenti memberikan ide untuk pengembangan mutu pendidikan di tingkat universitas, serta mengembangkan inovasi penggunaan model IOC. Kekurangan penelitian ini adalah mahasiswa yang pada awalnya tidak memahami materi dan sintaks model IOC, akibatnya adalah kelalaian waktu penelitian.

\section{REFERENSI}

Andhika, Edi Md, dkk. 2013. Pengaruh Model Pembelajaran IOC Berbasis Media Audio Visual Animasi Terhadap Hasil Belajar IPS. 
Skripsi. Singaraja. Universitas Pendidikan Ganesha.

Arfinanti, Nurul. 2010. Implementasi Model IOC dalam Mencapai Belajar Tuntas Siswa Kelas VIII SMPN Muntilan pada Pembelajaran Matematika Pokok Bahasan Theorema Phytagoras. Skripsi. Yogyakarta. Universitas Islam Negeri Sunan Kalijaga.

Aryani, Esa. 2015. Pengaruh Penerapan Pembelajaran Kooperatif Tipe IOC Terhadap Aktifitas dan Prestasi Belajar Siswa Kelas VII Pada Mata Pelajaran IPA Biologi Pokok Bahasan Pencemaran dan Kerusakan Lingkungan. Skripsi. Mataram. Universitas Mataram.
Cahyanti, Oktavia. 2015. Pengaruh Model IOC Terhadap Kemampuan Menyelesaikan Masalah Keliling dan Luas Persegi dan Persegi Panjang Siswa Kelas III SDN Capurejo Kediri. Skripsi. Kediri. Universitas Nusantara PGRI.

Lie, Anita. 2002. Mempraktikkan Cooperative Learning di Ruang Ruang Kelas. Jakarta: Gramedia.

Lufri. 2007. Strategi Pembelajaran Biologi. Padang: UNP Press.

Peraturan Menteri Pendidikan Nasional. 2007. Standar Proses. Jakarta: Depdiknas.

Putranjawa, Pande Made Dwi. 2013. Pengaruh Penerapan Model Pembelajaran Kooperatif Tipe IOC Terhadap Hasil Belajar Siswa Kelas VII. Jurnal KARMAPATI Vol.2 No.6. Sawan. 